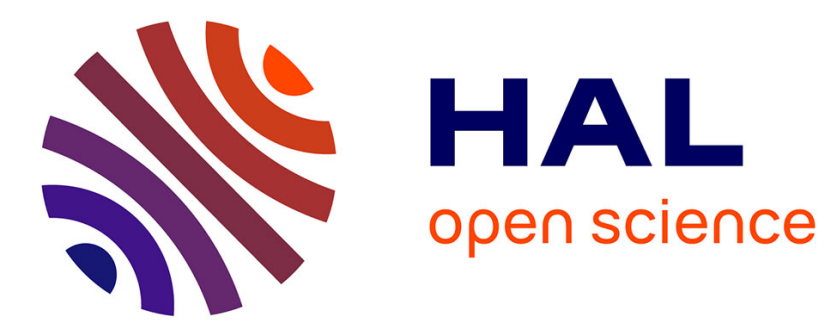

\title{
Increase in response rate by prolonged treatment with neoadjuvant letrozole
}

J. Michael Dixon, Lorna Renshaw, E. Jane Macaskill, Oliver Young, Juliette Murray, David Cameron, Gillian R. Kerr, Dean B. Evans, William R. Miller

\section{- To cite this version:}

J. Michael Dixon, Lorna Renshaw, E. Jane Macaskill, Oliver Young, Juliette Murray, et al.. Increase in response rate by prolonged treatment with neoadjuvant letrozole. Breast Cancer Research and Treatment, 2008, 113 (1), pp.145-151. 10.1007/s10549-008-9915-6 . hal-00478308

\section{HAL Id: hal-00478308 https://hal.science/hal-00478308}

Submitted on 30 Apr 2010

HAL is a multi-disciplinary open access archive for the deposit and dissemination of scientific research documents, whether they are published or not. The documents may come from teaching and research institutions in France or abroad, or from public or private research centers.
L'archive ouverte pluridisciplinaire HAL, est destinée au dépôt et à la diffusion de documents scientifiques de niveau recherche, publiés ou non, émanant des établissements d'enseignement et de recherche français ou étrangers, des laboratoires publics ou privés. 


\title{
Increase in response rate by prolonged treatment with neoadjuvant letrozole
}

\author{
J. Michael Dixon · Lorna Renshaw · E. Jane Macaskill · Oliver Young · \\ Juliette Murray · David Cameron · Gillian R. Kerr · Dean B. Evans · \\ William R. Miller
}

Received: 12 September 2007 / Accepted: 22 January 2008/Published online: 9 February 2008

(C) Springer Science+Business Media, LLC. 2008

\begin{abstract}
Purpose The aim of this study was to investigate the potential benefits of prolonged treatment with neoadjuvant letrozole. Patients and Methods About 182 consecutive patients have been treated in Edinburgh with neoadjuvant letrozole for 3 months or longer and 63 patients have continued on letrozole beyond 3 months. Outcomes are reported. Results Of the 63 patients who continued on letrozole, 38 patients took letrozole for more than 1 year and 23 took letrozole for more than 24 months. The median reduction in clinical volume in the first 3 months in these 63 patients was $52 \%$. Similar reductions in median clinical volume were seen between three to 6 months (50\%), 6-12 months and 12-24 months (medians 37 and $33 \%$, respectively). At 3 months $69.8 \%$ of the 182 patients had a partial or complete response. The response rate increased to $83.5 \%$ with prolonged letrozole treatment. Continuing letrozole beyond 3 months increased the number of women who initially required mastectomy or had locally advanced breast cancer who were subsequently suitable for breast conserving surgery from $60 \%$ (81/134) at 3 months to $72 \%$ (96/134). Thirty-three women remain on letrozole alone (man age at diagnosis 83 years) and at 3 years the median time to treatment failure has not been reached. Conclusion Continuing letrozole in responding patients beyond 3-4 months achieves further clinical reduction in tumour size. For elderly women with a short
\end{abstract}

J. M. Dixon $(\bowtie) \cdot$ L. Renshaw · E. J. Macaskill · O. Young ·

J. Murray · D. Cameron · G. R. Kerr · W. R. Miller

Edinburgh Breast Unit, Western General Hospital,

Edinburgh EH4 2XU, Scotland

e-mail: jmd@ed.ac.uk

D. B. Evans

Novartis Pharma AG, Klybeckstrasse 141, 4002 Basel,

Switzerland life expectancy letrozole alone may provide long-term disease control.

Keywords Breast conserving surgery - Endocrine therapy · Neoadjuvant · Letrozole · Large operable and locally advanced breast cancer

\section{Introduction}

Until recently neoadjuvant therapy of breast cancers consisted predominately of cytotoxic chemotherapy. References [1-4] Studies comparing neoadjuvant with adjuvant chemotherapy have shown that while disease-free, progression-free and overall survival are not changed by the timing of treatment, better outcomes are seen in patients who respond to neoadjuvant therapy [5-7]. These results highlight a key benefit of neoadjuvant therapy, the use of response to predict long-term outcome. Endocrine treatment is now emerging as an attractive alternative in postmenopausal women with large operable or locally advanced hormone receptor positive breast cancers, many of whom cannot tolerate the toxicities of chemotherapy.

Initial studies performed in Edinburgh suggested there may be benefits to using aromatase inhibitors rather than tamoxifen as neoadjuvant therapy in postmenopausal women with ER + cancers [8-9]. This led to a series of randomised trials. The $\mathrm{PO} 24$ trial compared 4 months treatment with neoadjuvant letrozole or tamoxifen in postmenopausal women with large hormone positive breast cancers that required mastectomy or were locally advanced [10]. Results from this study demonstrated that letrozole achieved a significantly higher clinical response rate $(55 \%$ vs. 36\%) and more patients treated with letrozole than with tamoxifen were suitable for breast-conserving surgery 
( $45 \%$ vs. $35 \%$ ). Letrozole now had a product licence in the UK for neoadjuvant use. Subsequent studies have been performed with anastrozole and exemestane treating patients for between 3 and 4 months prior to surgery and showed that compared with tamoxifen both drugs increased the number of patients becoming eligible for breast conserving surgery $[11,12]$.

The 3-4 months treatment duration of neoadjuvant endocrine therapy was based largely on experience with neoadjuvant chemotherapy, but more recent studies with longer durations of neoadjuvant chemotherapy suggest prolonging treatment duration increases the overall response rate [13]. There are a number of issues that need to be addressed with regard to neoadjuvant hormone therapy: do longer durations of treatment produce prolonged tumour shrinkage, do they increase the numbers achieving a response and do they increase the number of patients who become eligible for breast-conserving surgery? Furthermore, is letrozole alone a satisfactory long-term treatment for some patients with breast cancer? The aims of the present study were to review retrospectively the Edinburgh experience of patients treated with neoadjuvant letrozole to assess first whether patients continue to respond beyond the usual 3-4 months treatment period, and second to identify how many patients treated with long-term letrozole alone become resistant to letrozole and require a change of therapy.

\section{Patients and methods}

About 182 patients with large operable or locally advanced oestrogen receptor rich breast cancers have been treated consecutively with neoadjuvant letrozole for 3 months or longer in the Edinburgh Breast Unit. These patients have been treated since the issue of a licence for the use of letrozole in the neoadjuvant setting and do not include the series of patients presented in our early publications [14]. The aim of studying this series of patients was to identify factors associated both with response to therapy and longterm outcome. This study was approved by the local Ethics Committee and the Research and Development Department of the hospital. All women were postmenopausal, defined as amenorrhea for 1 year or with oestradiol, luteinising hormone and follicular stimulating hormone levels in the postmenopausal range. The mean age of the 182 patients was 76.5 years with a median of 78 and a range of 55-95 years. All had ER Allred scores between 5 and 8 with the majority having Allred scores of 8 (121) or 7 (59). All patients were treated with $2.5 \mathrm{mg}$ of letrozole.

Patients were reviewed initially after 2, 6 and 12 weeks of treatment to assess tolerance and to measure response by clinical measurement with callipers and imaging (ultrasound and clinical measurements at 0,6 and 12 weeks and mammography at 0 and 12 weeks). At 3 months all patients were reviewed by a single surgeon and a treatment decision taken. The decision was either to perform surgery, to continue letrozole, or following discussion at a multidisciplinary meeting to switch to another therapy. This decision was based on an assessment of response, operability, fitness for operation and willingness of the patient to proceed to surgery. Patients who continued letrozole beyond 3 months were reviewed at 6, 9, 12, 18 and 24 months and yearly thereafter.

Clinical and ultrasound volumes were calculated using the formula $\pi D^{3} / 6$ where ' $D$ ' is the mean diameter of two perpendicular measurements on clinical or mammographic assessment and the mean of two diameters and the depth measurement on ultrasound. A patient with no clinical mass palpable after 3 months was considered as having $100 \%$ reduction in clinical volume or a complete clinical response. The $\%$ change in clinical volume was calculated using the formula $100 x$ (initial volume - final volume) $\div$ initial volume. The change in volume between 3 and 6 months was calculated using the following formula: 100x (volume at 6 months - volume at 3 months $) \div$ (volume at 3 months) and other volumes were calculated similarly. Changes in volume were calculated for the first 3 months, between 3 and 6 months, between 6 and 12 months and between 12 and 24 months. These data were entered into an Excel spreadsheet and plotted using Minitab v.14. Time to treatment failure for the group taking letrozole longer than 6 months was calculated using a Kaplan-Meier estimate; the minimum treatment duration was 6 months and the maximum 5 years.

\section{Results}

The clinical response rates and outcomes at 3 months for all 182 patients are shown in Tables 1 and 2 . One hundred and twenty seven patients $(69.8 \%)$ had a complete or partial response and only four patients had disease progression ( $>25 \%$ increase in tumour volume). Complete clinical responses were only seen in patients with $\mathrm{T} 1$ and T2 cancers and no patient with a T3 or T4 cancer had a complete clinical response at 3 months. The four patients with progression of their disease were treated with surgery, three requiring mastectomy and one being successfully treated by breast conserving surgery. Of the 119 patients who had surgery at 3 months, 99 had breast conserving surgery and 19 had mastectomy. The 19 undergoing mastectomy included 15 patients who had locally advanced breast cancer which was not initially considered suitable for surgery but these patients became operable following 3 months of letrozole. Three had progressive disease and the final patient had an invasive lobular cancer that reduced 
Table 1 Tumour response after 3 months of letrozole according to WHO criteria

\begin{tabular}{lcl}
\hline Response & Number of patients & Percentage \\
\hline Complete response & 21 & 11.5 \\
Partial response & 106 & 58.3 \\
Static disease & 51 & 28 \\
Progressive disease & 4 & 2.2 \\
\hline
\end{tabular}

Response rate $69.8 \%$

in size but still required mastectomy. All 16 responding patients who had a mastectomy were considered unlikely to ever be candidates for breast conserving surgery even if they had continued to respond.

\section{Conversion to breast conserving surgery}

One hundred and thirty-four of the 182 patients had a cancer that either required mastectomy or was locally advanced at the outset of treatment. By 3 months 81 of these $134(60 \%)$ were suitable for and had breast conserving surgery.

Results for patients on prolonged letrozole treatment

Sixty-three patients continued on letrozole beyond 3 months for the following reasons: 26 were responding but had not responded sufficiently to allow breast-conserving surgery, 15 patients were responding but still had inoperable disease, 13 were unfit and considered unsuitable for surgery and nine refused surgery. The mean age of these 63 patients was 77.9 years (median 79) which is not significantly different from the age of the patients who had surgery at 3 months, mean age 75.7 years (median 77) comparison between two groups $P=0.09$. The initial T stage of patients who continued on letrozole was significantly different from that of the initial $\mathrm{T}$ stage of patients who had surgery at 3 months with significantly more patients having $\mathrm{T} 4$ cancers in the group continuing on surgery, $P=0.021$ (Table 3 ). Twenty per cent of patients with $\mathrm{T} 1$ cancers, $29 \%$ with $\mathrm{T} 2,35 \%$ with $\mathrm{T} 3$ cancers and $47 \%$ of patients with $\mathrm{T} 4$ cancers continued on letrozole for longer than 3 months. Of the 63 patients who continued letrozole beyond 3 months, the duration of letrozole in 25 was less than 1 year; the remaining 38 patients took letrozole for more than 1 year and 23 took letrozole for more than 24 months.

The mean reduction in clinical volume in the first 3 months in these 63 patients was $46.7 \%$, with a median of $52 \%$. There was a similar continued reduction in clinical

Table 3 T-stage of overall group and patients who underwent surgery at 3 months or continued letrozole

\begin{tabular}{lccc}
\hline & $\begin{array}{l}\text { Overall } \\
\text { group } \\
N(\%)\end{array}$ & $\begin{array}{l}\text { Patients } \\
\text { continuing } \\
\text { on letrozole } \\
N(\%)\end{array}$ & $\begin{array}{l}\text { Patients having } \\
\text { surgery at } \\
3 \text { months } \\
N(\%)\end{array}$ \\
\hline $\mathrm{T}_{1}$ & $10(5.5)$ & $3(4.8)$ & $7(5.9)$ \\
$\mathrm{T}_{2}$ & $91(50.0)$ & $28(44.4)$ & $63(52.9)$ \\
$\mathrm{T}_{3}$ & $23(12.6)$ & $5(7.9)$ & $18(15.1)$ \\
$\mathrm{T}_{4}$ & $58(31.9)$ & $27(42.9)$ & $31(26.1)$ \\
Total & $182(100)$ & $63(100)$ & $119(100)$ \\
\hline
\end{tabular}

$N$ represents the numbers of patients with $\mathrm{T}_{1}, \mathrm{~T}_{2}, \mathrm{~T}_{3}$ and $\mathrm{T}_{4}$ cancers in each of the groups. $\mathrm{T}_{4}$ includes direct skin infiltration

There were significantly less $\mathrm{T}_{4}$ cancers in those who proceeded with surgery compared to those continuing on letrozole, $P=0.021$, $\chi^{2}=5.359$

Table 2 Outcomes at 3 months for all patients treated with neoadjuvant letrozole

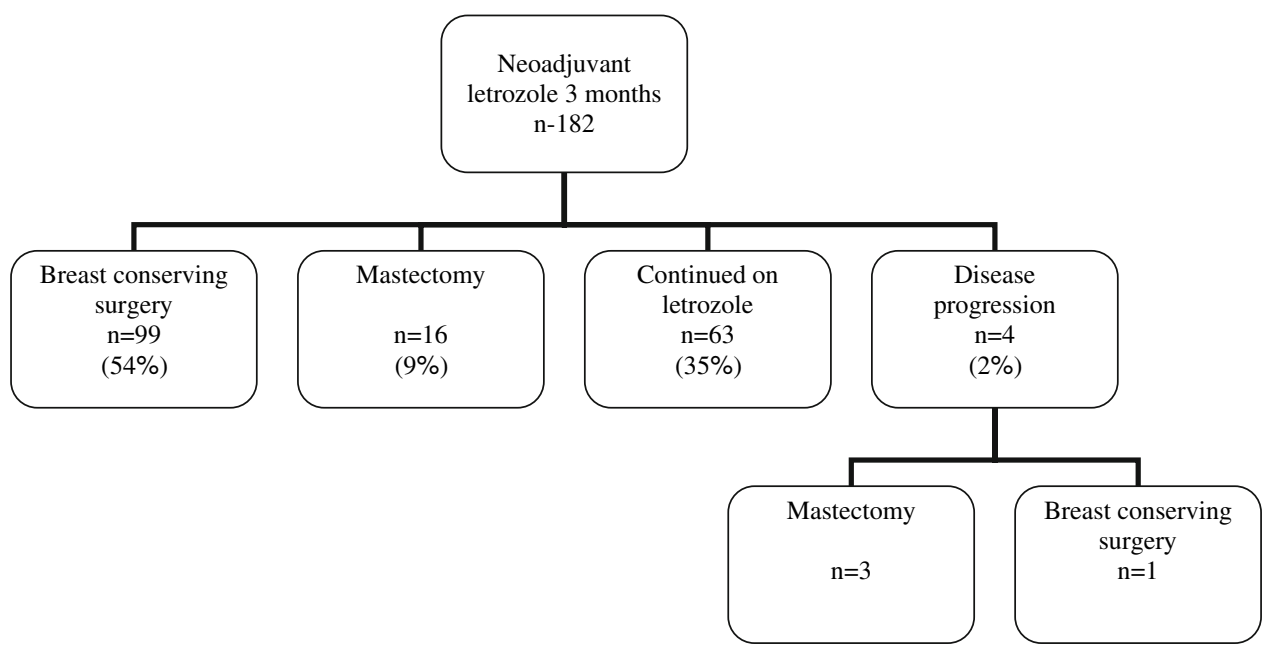


volume between 3 and 6 months (mean $46.6 \%$ median $50 \%$ ), between 6 and 12 months (mean 47.8\%, median $37 \%$ ) and 12-24 months (mean 35.8\%, median 33\%). Changes in clinical volume for individual patients who continued on letrozole for longer than 3 months are shown in Fig. 1 and summarised in Fig. 2. The changes in volume as assessed by ultrasound are shown in Fig. 3 and summarised in Fig. 4. There were four patients from 3 to 6 months where clinical or ultrasound assessment indicated that the tumour volume had increased in volume by $>25 \%$. In three of these patients other assessments including mammography and clinical measurement suggested the lesion was either static or smaller so treatment with letrozole was continued. None of these three showed progression at later assessments. From 6 to 12 months there were three patients whose tumours increased in size on ultrasound. Clinical assessment and mammography suggested there had been no significant change in size in two and both patients were infirm and unfit for surgery, so treatment with letrozole was continued and subsequently

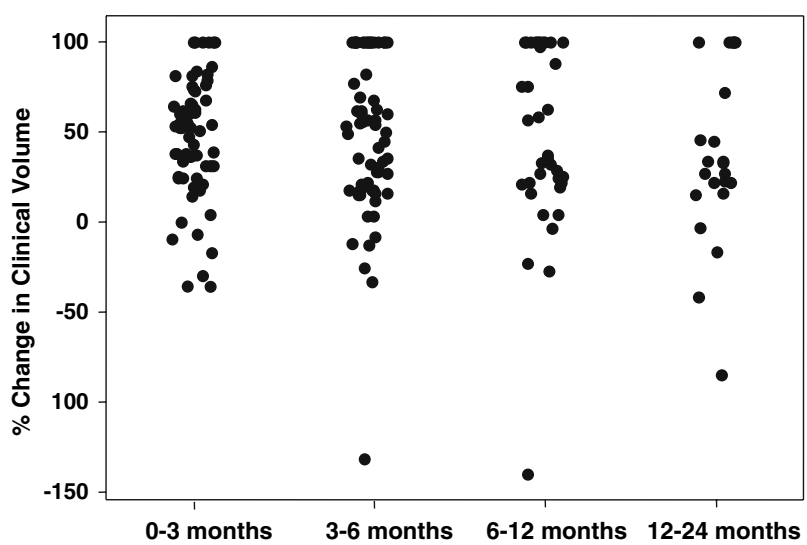

Fig. 1 Individual values for $\%$ reduction in clinical volume between time intervals $0-3$ months, 3-6 months, 6-12 months and 12-24 months

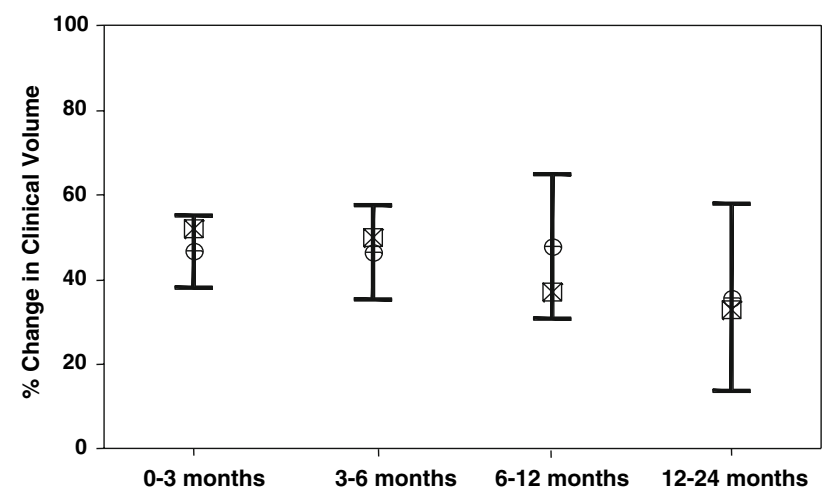

Fig. 2 Mean (circles) and median (squares) values with 95\% confidence intervals of the mean for change in clinical volume between 0 and 3 months, 3 and 6 months, 6 and 12 months and 12 and 24 months their disease has been static. Between 12 and 24 months, three patient's tumours did increase in size, one by $41 \%$, one by $42 \%$ and one by $85 \%$ on ultrasound. These tumours were increasing on other assessments. Two of these patients underwent surgery and the third had a change in hormonal treatment.

Best response for all 182 patients is shown in Table 4. By giving patients letrozole for longer than 3 months, the overall response rate in all 182 patients increased from $69.8 \%$ at 3 months to $83.5 \%$. The complete response rate in the 63 patients who continued letrozole was three of 63

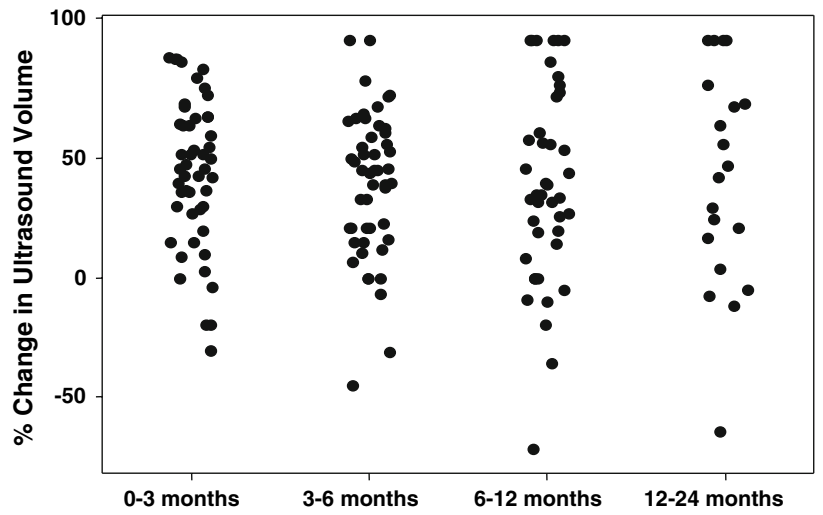

Fig. 3 Individual values for $\%$ reduction in ultrasound volume between 0 and 3 months, 3 and 6 months, 6 and 12 months and 12 and 24 months

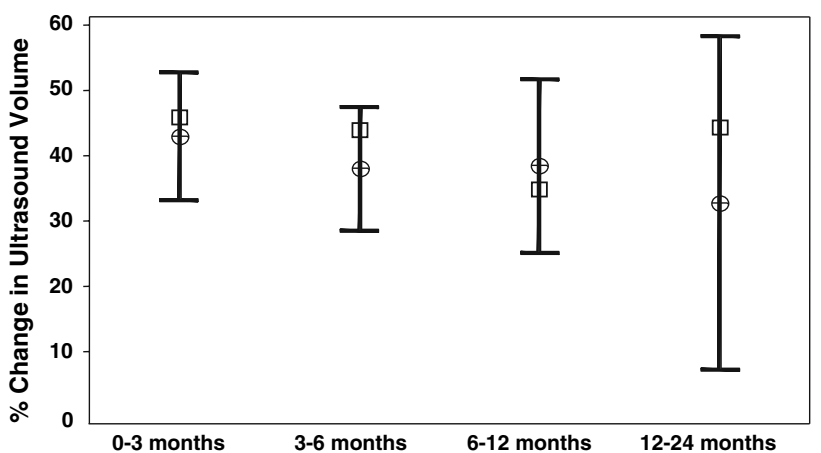

Fig. 4 Mean (circles) and median (squares) values with 95\% confidence intervals of the mean for change in ultrasound volume between 0 and 3 months, 3 and 6 months, 6 and 12 months and 12 and 24 months

Table 4 Best response for all 182 patients treated with 3 months or longer of neoadjuvant letrozole

\begin{tabular}{lcc}
\hline & Number of patients & Percentage \\
\hline Complete response & 34 & 18.7 \\
Partial response & 118 & 64.8 \\
Static disease & 26 & 14.3 \\
Progression & 4 & 2.2 \\
\hline
\end{tabular}


(4.8\%) at 3 months, six of 63 at 6 months (9.5\%), 11 of 38 at 12 months $(29 \%)$ and seven of $23(30 \%)$ at 2 years.

Of the 63 patients treated with letrozole for longer than 3 months, 21 patients eventually underwent surgery (15 breast conserving procedures and six mastectomies), two patients continued letrozole treatment but had radiotherapy for responding but locally advanced disease, seven switched to other hormonal therapies and 33 women remain on letrozole and their disease is currently controlled on this treatment alone. The mean age of this group at diagnosis was 83 years with a median of 84 years.

Prolonged treatment with neoadjuvant letrozole treatment resulted in an increase in the number of patients who were converted from requiring a mastectomy or who were inoperable to be suitable for breast conserving surgery from 81 of $134(60 \%)$ at 3 months with 96 (72\%) eventually being treated with breast conservation.

Time to treatment failure

The median period of follow up of those on prolonged letrozole was short at 3 years and at this time, the median time to treatment failure had not been reached with over $70 \%$ having their disease controlled on letrozole alone.

\section{Discussion}

In the late 1970 s and early 1980 s it was common practice to treat patients over the age of 70 years with tamoxifen alone and not consider them for surgery. A series of randomised trials compared tamoxifen alone versus surgery alone [15-17] and a recent meta-analysis comparing surgery with primary endocrine therapy for operable breast cancer in elderly women found no difference in overall survival [18]. Several randomised trials compared tamoxifen alone with surgery followed by tamoxifen and in all but one of these trials there was a significant increase in local events in the tamoxifen alone group [19-23]. One study also showed a significantly higher mortality in patients treated by tamoxifen alone but this increase in mortality was only apparent after 3 years of follow up [11]. A meta-analysis found a non-significant trend in favour of combining surgery with tamoxifen versus tamoxifen alone for overall survival (HR 0.86, $P=0.06$ ) and a significant improvement in local disease control in favour of surgery and tamoxifen (HR 0.28, $P<0.00001$ ) [18]. Many of these early studies did not select patients based on oestrogen receptor status and all used tamoxifen.

With the advent of the new aromatase inhibitors which are superior to tamoxifen in the neoadjuvant setting both in terms of response rates and converting patients to breast conserving surgery $[10-12,24]$ there has been a renewed interest in using hormonal therapy to treat elderly patients either prior to surgery or as a sole treatment. The only data available on the use of aromatase inhibitors are from series or from randomised neoadjuvant trials which have treated patients for between three and 4 months [10-12]. Studies which have used longer durations of neoadjuvant chemotherapy have shown that in comparison to the standard 3 months treatment, longer durations increase the rates of complete pathological response [13]. It was our perspective that longer durations of treatment with aromatase inhibitors might have a similar effect. The current study provides the first data from a sufficiently large group of patients treated for prolonged periods with neoadjuvant letrozole to confirm that prolonged treatment does produce continued tumour shrinkage and improves response rates.

In the current report the majority of patients who continued on letrozole had continuing reductions in tumour volume for up to 2 years. This review has also demonstrated that if there was evidence of tumour shrinkage by 3 months but the tumour remained inoperable or was only suitable for treatment by mastectomy prolonging treatment allowed more tumours to become operable and to become treatable by breast conserving surgery rather than mastectomy. Continued response occurred in the majority, but not in all patients and small numbers of women whose tumours initially responded to letrozole did become resistant and started to increase in size. Based on these observations it is our current practice to advise patients to undergo surgery if the cancer having been locally advanced becomes operable or if a cancer that is best treated initially by mastectomy becomes suitable for breast conserving surgery. Importantly in this study the majority of patients had oestrogen receptor rich tumours having ER Allred scores of 7 and 8 and only occasional patients had ER scores of 5 or 6 . Such selection is important because we have previously demonstrated that the highest rates of tumour shrinkage are in patients whose tumours have the highest levels of ER [24, 25]. While aromatase inhibitors do show activity even in tumours with low levels of ER, response rates, tumour shrinkage and reduction in proliferation are less than in tumours with high levels of ER [24].

Thirty-three patients out of the 63 who were treated for longer than 3 months remain on letrozole alone. Some of these women have been on letrozole for 5 years. These are an elderly population, median age 84 years, and many have co-morbidities. As with tamoxifen, there is likely to be a group of women whose tumours can be controlled for prolonged periods by letrozole alone [26]. Using microarray we have identified genes at diagnosis and genes which change early during treatment which correlate with response [27]. This approach may provide an opportunity to identify groups of women whose disease can be controlled on this treatment alone. 
Clinical assessment unless carried out by the same individual is open to interobserver error. The combination of clinical examination, ultrasound and mammography was invaluable in assessing response in the present series. In individual patients during prolonged treatment with letrozole on occasions one method of assessment indicated disease progression, whereas the two other assessments indicated that the tumour was adequately controlled. In such patients treatment with letrozole was continued and in all such patients the next series of assessments indicated that the disease remained controlled by the drug. Multimodality assessment in patients treated by endocrine therapy alone is therefore necessary.

This study has demonstrated that in carefully selected patients, neoadjuvant endocrine therapy with letrozole produces prolonged tumour shrinkage over many months and years. The optimal duration of letrozole is not clear and the decision on the duration of treatment should be individualised. Unless a patient refuses surgery or is considered to have significant morbidities which limit surgical options or there is limited life expectancy, then following a satisfactory response to neoadjuvant letrozole therapy surgery should be performed followed by postoperative radiotherapy in appropriate patients. Treatment by neoadjuvant letrozole to allow breast conserving surgery is associated with good long-term disease control rates providing postoperative radiotherapy is given [28]. In patients who are not suitable for or who refuse surgery, neoadjuvant letrozole given for prolonged periods appears safe and appears to provide this small group of women with longterm disease control.

Acknowledgements Thanks to the Dunhill Medical Trust who provided research Fellowships to Juliette Murray and Oliver Young. This work was supported in part by an unlimited educational grant from Novartis Pharma.

\section{References}

1. Bear H (1998) Indications for neoadjuvant therapy for breast cancer. Semin Oncol 25(Suppl 3):S3-S12

2. Perloff M, Lesnick GJ (1982) Chemotherapy before and after mastectomy in stage III breast cancer. Arch Surg 117:879-881

3. Schick P, Goodstein J, Moor J et al (1983) Preoperative chemotherapy followed by mastectomy for locally advanced breast cancer. J Surg Oncol 22:278-282

4. Bonadonna G, Veronesi U, Brambilla C et al (1990) Primary chemotherapy to avoid mastectomy in tumors with diameters of $3 \mathrm{~cm}$ or more. J Natl Cancer Inst 82:1539-1545

5. Cleator SJ, Makris A, Ashley SE, Lal R, Powles TJ (2005) Good clinical response of breast cancers to neoadjuvant chemoendocrine therapy is associated with improved overall survival. Ann Oncol 16:267-272

6. van der Hage JA, van de Velde CJH, Julien JP et al (2001) Preoperative chemotherapy in primary operable breast cancer: results from the European Organization for Research and Treatment of Cancer Trial 10902. J Clin Oncol 19(22):4224-4237

7. Wolmark N, Wang J, Mamounas E, Bryant J, Fisher B (2001) Preoperative chemotherapy in patients with operable breast cancer: nine-year results from National Surgical Adjuvant Breast and Bowel Project B-18. J Natl Cancer Inst Monogr 30:96-102

8. Dixon JM, Love CDB, Bellamy COC, Cameron DA, Leonard RCF, Smith H, Miller WR (2001) Letrozole as primary medical therapy for locally advanced and large operable breast cancer. Breast Cancer Res Treat 66(3):191-199

9. Dixon JM, Jackson J, Renshaw L, Miller WR (2003) Neoadjuvant tamoxifen and aromatase inhibitors: comparisons and clinical outcomes. J Steroid Biochem Mol Biol 86:295-299

10. Eiermann W, Paepke S, Appfelstaedt J et al (2001) Preoperative treatment of postmenopausal breast cancer patients with letrozole: a randomized double-blind multicenter study. Ann Oncol 12(11):1527-1532

11. Smith I, Dowsett M, Ebbs SR (2005) On behalf of the IMPACT Trialists: Neoadjuvant treatment of postmenopausal breast cancer with anastrozole, tamoxifen, or both in combination: the Immediate Preoperative Anastrozole, Tamoxifen, or Combined with Tamoxifen (IMPACT) multicentre, double-blind randomized trial. J Clin Oncol 23(22):4842-4844

12. Semiglazov VF, Semiglazov VV, Ivanov VG et al (2005) Neoadjuvant endocrine therapy: exemestane vs tamoxifen in postmenopausal ER + breast cancer patients (T1-4, N1-2, M0). Proc Am Soc Clin Oncol 23(16s):Abstract 530

13. Bear HD, Anderson S, Smith RE et al (2004) A randomized trial comparing preoperative doxorubicin/cyclophosphamide (AC) to preop AC followed by docetaxel (T) and to preop AC followed by postoperative $\mathrm{T}$ in patients with operable carcinoma of the breast: results of NSABP B-27. Breast Cancer Res Treat 88(suppl 1): S16, Abstract 26

14. Dixon JM, Love CDB, Bellamy COC et al (2001) Letrozole as primary medical therapy for locally advanced and large operable breast cancer. Br Ca Res Treat 66(3):191-199

15. Gazet JC, Ford HT, Coombes RC et al (1994) Prospective randomized trial of tamoxifen vs surgery in elderly patients with breast cancer. Eur J Surg Oncol 20(3):207-214

16. Kenny FS, Robertson JFR, Ellis IO et al (1998) Long-term follow-up of elderly patients randomised to primary tamoxifen or wedge mastectomy as initial therapy for operable breast cancer. Breast 7:335-339

17. Fentiman IS, Christiaens MR, Paridaens R et al (2003) Treatment of operable breast cancer in the elderly: a randomised clinical trial EORTC 10851 comparing tamoxifen alone with modified radical mastectomy. Eur J Cancer 39:306-316

18. Hind D, Wyld L, Beverley CB, Reed MW (2007) Surgery versus primary endocrine therapy for operable primary breast cancer in elderly women (70 years plus). Cochrane Database of Systematic Reviews Issue 2

19. Mustacchi G, Ceccherini R, Milani S et al (2003) Tamoxifen alone versus adjuvant tamoxifen for operable breast cancer of the elderly: long-term results of the phase III randomized controlled multicenter GRETA trial. Ann Oncol 14(3):414-420

20. Fennessy M, Bates T, MacRae K et al (2004) on behalf of the Closed Trials Working Party of the Cancer Research UK Breast Cancer Trials Group: Late follow-up of a randomized trial of surgery plus tamoxifen versus tamoxifen alone in women aged over 70 years with operable breast cancer. Br J Surg 91(6):699_ 704

21. Bates T, Fennessy M, Riley DL et al (2001) On behalf of the CRC Breast Cancer Trials Group UK: Breast Cancer in the Elderly: Surgery improves survival. The results of a Cancer Research Campaign Trial. Eur J Cancer 37(suppl 5):0-19 
22. Willsher PC, Robertson JFR, Jackson L, al Hilaly M, Blamey RW (1997) Investigation of primary tamoxifen therapy for elderly patients with operable breast cancer. Breast 6:150-154

23. Capasso I, Nuzzo F, Labonia V, Landi G, Rossi E, de Matteis A (2000) Surgery and tamoxifen versus tamoxifen as treatment of stage I and II breast cancer in over 70 years old women: Ten years follow-up. Ann Oncol 11(suppl 4):20

24. Ellis MJ, Coop A, Singh B et al (2001) Letrozole is more effective neoadjuvant endocrine therapy than tamoxifen for erbB-1 and/or erbB-2 positive, estrogen receptor positive primary breast cancer: evidence from a phase III randomised trial. J Clin Oncol 19(18):3808-3816
25. Macaskill EJ, Dixon JM (2007) Neoadjuvant use of endocrine therapy in breast cancer. Breast 13(3):243-250

26. Horobin JM, Preece PE, Dewar JA et al (1991) Long-term follow-up of elderly patients with locoregional breast cancer treated with tamoxifen only. Br J Surg 78(2):213-217

27. Miller WR, Krause A, Evans DB et al (2005) Phenotypes for endocrine resistance can be indentified by RNA microarray of sequential biopsies and are more variable than those predicting for tumour response. Breast Cancer Res Treat 94(suppl 1):S17, Abstract 31

28. Dixon JM (2005) Surgical issues surrounding the use of aromatase inhibitors. J Steroid Biochem Mol Biol 95:97-103 